\title{
Managing HIV infection in patients older than 50 years
}

\author{
Jacqueline M. McMillan MD, Hartmut Krentz PhD, M. John Gill MB ChB, David B. Hogan MD
}

Cite as: CMAJ 2018 October 22;190:E1253-8. doi: 10.1503/cmaj.171409

A ntiretroviral therapy has extended the life expectancy of people living with $\mathrm{HIV}^{1-4}$ although disparities remain. Patients who are not white, who begin antiretroviral therapy with CD4 cell counts below 350 cells $/ \mu \mathrm{L}$ or who use illicit intravenous drugs do not live as long: 5 however, the Centers for Disease Control and Prevention (CDC) estimated that, by 2020, more than half of all people living with HIV in the United States will be older than 50 years of age. ${ }^{6}$ The age threshold used to define older people living with HIV is 50 years.

Numbers of older people living with HIV have also increased in Canada. In 1997, $10 \%$ of patients receiving HIV care at the Southern Alberta Clinic in Calgary were older than 50 years of age; in 2017 , such patients accounted for $48 \%$ of care recipients. The primary reason for this change is the aging of people who acquired infection earlier in life. However, adults older than 50 years of age now account for almost one in six new HIV infections in Canada and the US. ${ }^{5-7}$

There are distinct differences between people who are aging with HIV and patients who seroconvert in older age. ${ }^{8}$ People who have aged with HIV infection have high rates of comorbid illness at younger ages than people without HIV infection, which leads to increased complexity in the provision of clinical care. Here, we focus on aging with HIV, exploring the effects of many years of infection and treatment on the development and progression of comorbidities. We provide guidance for nonspecialist physicians who are increasingly likely to be involved in the prevention and management of non-HIV related comorbidities in patients older than 50 years. We particularly draw on recent evidence from randomized controlled trials and large cohort and case-control studies (Box 1).

\section{What contributes to the burden of comorbidity in older patients with HIV and AIDS?}

Older people living with HIV are more likely to have complicating comorbidities and polypharmacy, leading to possible drug-disease and drug-drug interactions that can be complicated by age-related pharmacokinetic and pharmacodynamic changes. The risk of resistance to antiretroviral therapy and toxicity is increased because of the long duration of infection. ${ }^{\text {? }}$

Observational studies have estimated that the prevalence of select age-related comorbidities among these patients approaches

\section{KEY POINTS}

- The population of patients living with HIV and AIDS is aging as a result of both longer life expectancies with infection and an increase in newly acquired infections at older ages.

- Sexually active older adults should be considered to undergo HIV screening.

- Age-related conditions and comorbidities (e.g., frailty, neurocognitive impairment, cardiovascular disease, hypertension, dyslipidemia, renal disease, osteoporosis and fractures) develop at younger ages and more often among patients living with HIV and AIDS than among patients without HIV infection.

- Clinical care for patients living with HIV and AIDS is evolving, with an increasing focus on dealing with age-related non-HIV comorbidities and drug-related issues in addition to continued viral suppression.

that seen among people without HIV infection who are 5 years older, ${ }^{9}$ and the risk of multimorbidity for these patients is similar to that of people without HIV infection who are 10-15 years older. ${ }^{10}$ One study found that patients older than 45 years of age living with HIV had higher multimorbidity than was seen in those with a new infection who were of a similar age. ${ }^{11}$ However, it is not clear whether the relatively earlier occurrence of comorbidities among people living with HIV is the result of accelerated or accentuated aging. ${ }^{12}$ In the former, the aging process itself

\section{Box 1: Evidence used in this review}

We performed a narrative literature review of the broad topic "aging with HIV," with the goal of exploring various aspects of this topic. We searched MEDLINE databases using combinations of the terms "aged," "middle-aged," "older," and "HIV," "human immunodeficiency virus," "AIDS," "Acquired Immune Deficiency Syndrome," with no date or language restrictions. Our initial search produced 1117 articles. We screened titles and abstracts for relevance, and removed duplicates, after which we selected 623 unique citations for review that we categorized by topic (e.g., HIV and aging/cardiovascular disease [37 unique citations]). We searched the reference lists of included articles for additional relevant studies. We focused on the most recent studies, in particular randomized controlled trials, large cohort studies and case-control studies. A descriptive synthesis of the results of this search is provided. 
speeds up, leading to the earlier onset of age-related conditions; with the latter, these conditions are more likely to develop, but at expected ages. Whatever the contributing factors, care for these patients should incorporate helping them cope with multiple non-HIV related chronic diseases at relatively younger ages, in addition to continuing to treat and manage HIV/AIDS. ${ }^{13}$

\section{Which specific comorbidities present a challenge?}

\section{Cardiovascular disease}

The relative risk of cardiovascular disease among people living with HIV who have received antiretroviral therapy is about twofold greater than for those of a similar age with no HIV infection. ${ }^{14}$ There is a $40 \%-50 \%$ higher incidence of myocardial infarction among people with HIV after controlling for traditional cardiovascular disease risk factors. ${ }^{15}$ Both higher viral loads and lower CD4 counts are independently associated with this increased risk for ischemia. ${ }^{16}$ The incidence of myocardial infarctions in people living with HIV declined in the late 1990s, possibly as a result of better management of HIV and vascular risk factors. ${ }^{17}$ However, with increases in life expectancy for people living with HIV, it will be important to proactively manage risk factors for cardiovascular disease to effectively prevent disease.

\section{Chronic kidney disease}

Risk factors for chronic kidney disease among people living with HIV include older age, being a woman, diabetes mellitus, hypertension, dyslipidemia, CD4 cell count below 200 cells $/ \mu \mathrm{L}$, AIDS, low baseline creatinine, exposure to tenofovir, ${ }^{18}$ heart failure, being black, Hepatitis C (HCV) infection and alcohol misuse. ${ }^{19}$ The prevalence of chronic kidney disease appears to be decreasing, possibly owing to improved antiretroviral therapy regimens and increased use of renoprotective agents (i.e., angiotensin-converting enzyme inhibitors, angiotensin receptor blockers)..$^{20} \mathrm{~A}$ recent Australian database study estimated that chronic kidney disease (estimated glomerular filtration rate $<60 \mathrm{~mL} / \mathrm{min}$ per $1.73 \mathrm{~m}^{3}$ ) affects about 1 in 20 in this population. ${ }^{21}$ Consideration of early chronic kidney disease is important, because its presence should prompt the avoidance or dosage adjustment of certain medications.

\section{Metabolic syndrome and diabetes}

People living with HIV are more likely to have certain components of the metabolic syndrome (i.e., diabetes, hypertension, and higher triglyceride levels and high-density lipoprotein levels) than those without HIV infection. ${ }^{22}$ Cumulative exposure to older, more metabolically toxic antiretroviral therapies was associated with a higher likelihood of incident diabetes. ${ }^{8,23,24}$ Both diabetes prevalence and incidence were as much as fourfold higher for men with HIV who were receiving antiretroviral therapy than for men without HIV. ${ }^{25}$ Whether the newer, less metabolically toxic therapies are associated with a lower likelihood of diabetes, hypertension and dyslipidemia is unknown.

\section{Cancer}

Mortality attributable to non-AIDS related, non-hepatitis related cancers (particularly of the lung) increased from $11 \%$ to $22 \%$ among people living with HIV in France between 2000 and 2010. ${ }^{26}$ The increased incidence of lung and anal cancers among patients with HIV and AIDS may be suggestive of rates of smoking and infection with human papillomavirus (HPV). ${ }^{27}$ With greater use of antiretroviral therapy and the advancing age of this patient population, non-HIV related malignant diseases that are age-related or associated with lifestyle factors such as smoking are likely to increase, and should be screened for (Box 2). ${ }^{28-30}$

Screening recommendations for other cancers are less clear. Clinicians should likely defer to national screening guidelines, such as the Canadian Task Force guidelines for breast, colon, lung, prostate and hepatocellular cancers (https://canadiantaskforce.ca/ guidelines/published-guidelines/). Specific recommendations for people living with HIV have yet to be developed.

\section{Liver disease}

Results from a collaboration of 11 cohort studies involving more than 200 clinics in Europe, the US and Australia showed that liver disease is responsible for as many as one in five deaths among people living with HIV. ${ }^{31}$ Furthermore, HIV and HCV coinfection leads to faster progression to fibrosis and cirrhosis in addition to an increased risk of hepatocellular carcinoma compared with HCV monoinfection. ${ }^{32}$ However, a recent meta-analysis concluded that effective antiretroviral therapy may reduce liverrelated mortality among patients with dual infection. ${ }^{33}$ Most cases of HIV-HCV coinfection occur in patients who use illicit intravenous drugs. ${ }^{34}$ Odds of HCV infection are six times higher

Box 2: Advice on cancer screening for people aging with HIV and AIDS 29,30

- Cervical cancer

- Annual Papanicolaou (Pap) testing, unless two consecutive tests in a row are negative, after which screening can be done every three years*

- Human papillomavirus (HPV) cotesting for patients aged $\geq 30$ years

- Annual digital rectal and vaginal examinations, and visual inspection of external genitalia

- Anal cancer

- Annual history and physical examination for regional symptoms and previous abnormal examination findings (e.g., condyloma or changes in pigmentation), and digital rectal examination

- Referral to anoscopy and potential biopsy for women with abnormal cervical histology and anyone with abnormal findings on physical examination

- Pap testing at baseline and annually for men who have sex with men, women with a history of abnormal cervical histology and anyone with a history of anogenital condyloma

Note: Adapted with permission from the New York State Department of Health AIDS Institute (https://www.hivguidelines.org/).

*There is insufficient evidence to suggest stopping screening at 65 years of age. 
for people living with HIV, presumably because of shared risk factors (e.g., intravenous drug use), enhanced transmission of HCV among these patients and decreased clearance of HCV in patients with HIV who are not receiving antiretroviral therapy. ${ }^{34}$

Metabolic liver diseases, such as non-alcoholic fatty liver disease and non-alcoholic steatohepatitis, have become increasingly common among people living with HIV. ${ }^{35}$ A 2015 prospective cohort study of patients with HIV who showed persistent ( $\geq 6 \mathrm{mo}$ ) elevations in aminotransferase levels without evidence of viral hepatitis reported that $73 \%$ and $54 \%$ of patients had evidence of non-alcoholic fatty liver disease and non-alcoholic steatohepatitis, respectively; these rates are higher than those seen among patients without HIV and viral hepatitis who underwent biopsy for similar indications. ${ }^{36}$ Associations are reported between non-alcoholic steatohepatitis and fibrosis and insulin resistance and obesity, but not HIV or antiretroviral therapy duration or specific antiretroviral agents. ${ }^{36}$ Both infection with HIV and antiretroviral therapy may contribute to insulin resistance, dyslipidemia and atherosclerosis, which in turn may contribute to the risk for non-alcoholic steatohepatitis and non-alcoholic fatty liver disease. ${ }^{35}$

Specialist expertise in the selection of HIV antiretroviral therapy is needed for patients with a higher baseline risk of fatty liver disease because of pre-existing obesity, insulin resistance or dyslipidemia. ${ }^{35}$ The European AIDS Clinical Society (EACS) guidelines recommend baseline determinations and subsequent testing every 3-12 months for aspartate and alanine aminotransferase, alkaline phosphatase and bilirubin levels. ${ }^{37}$ In patients with HIV and non-alcoholic fatty liver disease who are overweight, weight loss of $7 \%-10 \%$, avoidance of processed foods and added fructose, and adherence to a Mediterranean diet are recommended. ${ }^{35}$ Nonalcoholic steatohepatitis and nonalcoholic fatty liver disease should be considered in adults with HIV who have liver disease, particularly in the absence of coinfection with hepatitis $\mathrm{B}$ virus or $\mathrm{HCV}$.

\section{Which syndromes associated with aging may occur earlier?}

\section{Neurocognitive impairment}

Profound immunosuppression, high viral loads and opportunistic infections are associated with HIV-related dementia, which is now recognized as the most severe end of a spectrum of cognitive impairment known as HIV Associated Neurocognitive Disorder. ${ }^{38}$ Although moderate to severe impairment has become less common with the widespread use of antiretroviral therapy, ${ }^{39}$ about one-third of patients with HIV or AIDS have at least subtle neurocognitive impairment, which is associated with deficits in attention, working memory, executive function, motor control, motor processing and information processing speed more often than impairments in short- and long-term memory and language abilities. ${ }^{40}$ Differentiating HIV Associated Neurocognitive Disorder from other causes of cognitive impairment, such as Alzheimer and cerebrovascular disease, is challenging yet important for determining prognosis and management. Cognitive impairment may compromise adherence to antiretroviral therapy and other aspects of care. ${ }^{41}$

\section{Frailty}

Frailty is common and occurs at an earlier age among people living with HIV; it is associated with higher risks of multimorbidity, admission to hospital or long-term care and death. ${ }^{42-44}$ How best to detect and manage frailty for these patients requires additional research.

\section{Osteoporosis and fractures}

Recent observational evidence has found that HIV infection is associated with about a twofold increased risk of fractures among men aged 50-59 years compared with men without HIV. ${ }^{45}$ Randomized controlled trials of older antiretroviral drugs showed more rapid decline of bone mineral density with continuous therapy. ${ }^{46}$ Proven risk factors for osteoporotic fractures among people living with HIV include older age and being white, as well as exposure to tenofovir and protease inhibitors. ${ }^{47,48}$ Evidence from randomized controlled trials suggests that alendronate is a safe and effective option for treating osteoporosis in patients with HIV and AIDS who are taking older continuous antiretroviral therapies. ${ }^{49}$ Guidelines recommend baseline bone mineral density screening for osteoporosis among postmenopausal women and men with HIV who are older than 50 years. ${ }^{50,51}$ These recommendations are based on studies conducted between 1988 and 2010 with older, potentially more toxic antiretroviral therapies and no adjustment for other osteoporosis risk factors (e.g., low body mass index, smoking, alcohol use, poor nutrition), which may be more common in people living with HIV. More current research and updated guidance are needed.

\section{What else may affect the health of older people living with HIV?}

\section{Falls}

About $30 \%$ of men living with HIV with a mean age of 52 years report falling during the previous year compared with a fall rate of $16 \%$ over two years in a community-based sample of 45 - to 65 -year-old men. ${ }^{52,53}$ Difficulty with tandem gait, prescribed drug use (i.e., antidepressant, sedative, opioid, didanosine), selfreported exhaustion, diabetes, female sex and weight loss are associated with future fall risk..$^{22}$ The combination of osteoporosis and falls markedly increases the risk of fragility fractures in the general population. ${ }^{54}$ Falls may also lead to fear of future falls, resulting in decreased mobility and deconditioning. Effective interventions for both osteoporosis and falls could decrease the risk of fractures and traumatic brain injury among people living with HIV, but further research is required.

\section{Polypharmacy}

Prescription of five or more non-antiretroviral medications is common among patients with HIV and AIDS, and exposes patients to a variety of adverse drug-drug interactions. ${ }^{55}$ In one populationbased study, $7 \%$ of patients with HIV had prescriptions for a contraindicated antiretroviral/non-antiretroviral combination, and $33 \%$ had prescriptions for a combination with moderate to high likelihood of an adverse reaction. ${ }^{56}$ In another study, $70 \%$ of patients were exposed to category D drug-drug interactions (i.e., 
an interaction that should prompt consideration of therapy change) and $11 \%$ were exposed to a category $\mathrm{X}$ interaction (i.e., a combination that should be avoided). ${ }^{57}$ Adverse effects can occur even after a drug is withdrawn, as exemplified in a recent case report describing adrenal insufficiency in a 65-year-old man whose ritonavir was discontinued while he remained on inhaled budesonide. ${ }^{58}$ Medication review (including consideration of overthe-counter and complementary agents) and careful communication between all prescribers and dispensers of medications can help minimize the risk of adverse interactions.

\section{Vaccinations}

Live vaccines are contraindicated for people living with HIV whose immune systems are suppressed or who have a CD4 count of 200 cells $/ \mu \mathrm{L}$ or less. Box 3 provides information on recommended vaccinations for older people living with HIV. ${ }^{50,59}$ Patients with other risk factors for liver disease (intravenous drug use, HCV coinfection) are at increased risk of acquiring hepatitis, and particular care should be taken to ensure that vaccinations for hepatitis $A$ and $B$ are received.

\section{Box 3: Recommended vaccinations for older adults} living with HIV ${ }^{59}$

- Annual influenza vaccine for all patients (inactivated injectable or live intranasal vaccine if the patient does not have immune suppression, preferably during autumn)

- Zoster live vaccine for patients aged $\geq 50$ years who have a CD4 cell count $\geq 200$ cells $/ \mu \mathrm{L}$; previous zoster infection is not a contraindication, but vaccination should wait until 1 year after last episode

- Pneumococcal vaccine for patients with CD4 cell count $\geq 200$ cells/ $\mu \mathrm{L}$ (single dose pneumococcal 13-valent conjugate [Prevnar], followed at least $8 \mathrm{wk}$ later by a single dose of pneumococcal polysaccharide [Pneumovax], with a booster dose of pneumococcal polysaccharide at least $5 \mathrm{yr}$ later)

- Hepatitis A vaccine for men who have sex with men, people who use drugs intravenously, travellers to endemic countries, patients with chronic liver disease, and patients with hepatitis $B$ or $C$ coinfection who are nonimmune to hepatitis A virus (single dose of monovalent vaccine, with a booster at least 6 mo later)

- Hepatitis B vaccine for all patients who have no evidence of past or current infection $(40 \mu \mathrm{g}$ of monovalent vaccine at 0,1 and $6 \mathrm{mo}$, with revaccination if postvaccination serology shows $\leq 10 \mathrm{IU} / \mathrm{L}$ anti-hepatitis B antibodies)

- Meningococcal vaccine for all patients* $(2$ doses of Men-CACYW 8 wk apart, and 2 doses of 4 CMenB at least 4 wk apart)

- Tetanus, diphtheria and pertussis vaccine for all patients (every $10 \mathrm{yr})$

- Hemophilus influenza type b vaccine for all patients (single dose recommended regardless of vaccination history)

All live vaccines (Bacillus Calmette-Guérin, herpes zoster, live influenza, measles-mumps-rubella, typhoid, varicella) are contraindicated in cases of advanced HIV and AIDS

Note: Adapted from the Government of Canada, Canadian Immunization Guide Part 3: Vaccination of Specific Populations..$^{59}$

*Neither vaccine is authorized for use in patients older than 50 years, but limited evidence and expert opinion suggest their use is considered appropriate.

\section{Depression, diminished health-related quality of life and social isolation}

HIV status has been independently associated with depression and poorer health-related quality of life. ${ }^{60}$ Observational evidence has highlighted higher rates of social isolation among people living with HIV, which worsens with age. ${ }^{61}$ Over time, more people with HIV may need to move into retirement homes or long-term care facilities. Qualitative research among older people living with HIV and AIDS in Ontario found concerns around their acceptance into retirement facilities, access to subsidized housing and homelessness. ${ }^{62}$ Homelessness is associated with reduced adherence to antiretroviral therapy, disease progression and HIV transmission. ${ }^{62} \mathrm{~A}$ recent scoping review on aging with HIV reported a lack of qualitative studies that explore the lived experiences of people aging with HIV and end-of-life care. ${ }^{63}$

\section{New HIV infection in older adults}

People more than 50 years of age now account for almost one in six people with a new HIV infection in Canada and the US. ${ }^{5-7}$ Clinicians should maintain a high index of suspicion for HIV infection throughout the lifespan, particularly among people with risk factors for infection. Rates of HIV testing decline with age ${ }^{64}$ with only $25 \%$ of Americans over 50 years of age reporting ever having been tested..$^{65}$ Barriers to testing include lack of awareness of HIV risk in older adults, discomfort among health care providers with speaking to older adults about sex, and beliefs that older adults are not sexually active. ${ }^{66}$ Facilitators of testing are patientinitiated requests for treatment of sexual dysfunction or infections. ${ }^{66}$ Older patients may not view themselves as being at risk, and they may associate condom use with pregnancy prevention rather than protection from sexually transmitted infections.

The Public Health Agency of Canada recommends one-time HIV testing of people who are or have been sexually active without age restrictions. ${ }^{67}$ The CDC recommends testing for adults less than 65 years of age at least once, with annual testing for higher risk populations. ${ }^{68}$

After HIV is diagnosed, antiretroviral therapy should start as soon as possible regardless of patient age. Because suboptimal treatment adherence (i.e., taking $<80 \%$ of drugs prescribed) is associated with poorer outcomes, it is important to take steps to optimize adherence. ${ }^{69}$ Overall, older adults with HIV are at lower risk of nonadherence, possibly because they are more accustomed to taking medications. ${ }^{70} \mathrm{~A}$ variety of factors, such as neurocognitive impairment, ${ }^{71}$ depressive symptoms, lower social support ${ }^{72}$ and comorbidity, ${ }^{55}$ may compromise medication adherence. Presence of these factors should lead to more intensive monitoring of therapy and use of aids to improve adherence (e.g., prompts or cues, linking medication taking with existing habits). ${ }^{73}$ People who inject drugs and people who live in less affluent areas have lagged in achieving the benefits possible with antiretroviral therapy, ${ }^{74}$ and should receive particular attention.

\section{Conclusion}

People are both aging with HIV infection and acquiring infection at older ages. Not everyone has benefitted from the 
improvements to mortality and quality of life that have arisen as a result of antiretroviral therapy. Continuing to provide comprehensive HIV care while addressing an increasing burden of agerelated, non-HIV related health conditions is a growing challenge. Future research will hopefully address gaps in existing knowledge (Box 4). The care for people aging with HIV and AIDS will increasingly involve nonspecialist health and social care personnel, who should be aware of the changing demographics of this patient population in Canada.

\section{Box 4: Unanswered questions}

- How do we improve sexual education of older adults and the people who care for them?

- How do we best care for an aging population of patients living with HIV and AIDS?

- Where is care best provided? Do we have the resources to provide multidisciplinary care?

- How do we prepare as a society for the future medical, social and housing needs of this vulnerable population?

- Should we be placing a greater focus on education of Canadians and clinicians in considering HIV among older adults to facilitate early identification and treatment?

- Should we be routinely screening for frailty and cognitive impairment among patients with HIV?

- How should we address the stigma associated with a diagnosis of HIV?

\section{References}

1. Mocroft A, Vella S, Benfield TL, et al. Changing patterns of mortality across Europe in patients infected with HIV-1. EuroSIDA Study Group. Lancet 1998;352:1725-30.

2. Mocroft A, Brettle R, Kirk O, et al.; EuroSIDA study group. Changes in the cause of death among HIV positive subjects across Europe: results from the EuroSIDA study. AIDS 2002;16:1663-71.

3. Lewden C, Chene G, Morlat P, et al.; Agence Nationale de Recherches sur le Sida et les Hepatites Virales (ANRS) CO8 APROCO-COPILOTE Study Group; Agence Nationale de Recherches sur le Sida et les Hepatites Virales (ANRS) CO3 AQUITAINE Study Group. HIV-infected adults with a CD4 cell count greater than 500 cells/ $\mathrm{mm}^{3}$ on long-term combination antiretroviral therapy reach same mortality rates as the general population. J Acquir Immune Defic Syndr 2007;46:72-7.

4. Eyawo O, Franco-Villalobos C, Hull MW, et al.; Comparative Outcomes And Service Utilization Trends (COAST) study. Changes in mortality rates and causes of death in a population-based cohort of persons living with and without HIV from 1996 to 2012. BMC Infect Dis 2017;17:174.

5. Samji H, Cescon A, Hogg RS, et al.; North American AIDS Cohort Collaboration on Research and Design (NA-ACCORD) of leDEA. Closing the gap: increases in life expectance among treated HIV-positive individuals in the United States and Canada. PLoS One 2013;8:e81355.

6. HIV among people aged 50 and over. Atlanta: US Centers for Disease Control and Prevention; 2018. Available: www.cdc.gov/hiv/group/age/olderamericans/index. html (accessed 2018 June 28).

7. Krentz HB, Gill MJ. Increased costs of HIV care associated with aging in an HIVinfected population. HIV Med 2015;16:38-47.

8. Ledergerber B, Furrer H, Rickenbach M, et al.; Swiss HIV Cohort Study. Factors associated with the incidence of type 2 diabetes mellitus in HIV-infected participants in the Swiss HIV Cohort Study. Clin Infect Dis 2007;45:111-9.

9. Schouten J, Wit FW, Stolte IG, et al.; AGEhIV Cohort Study Group. Cross-sectional comparison of the prevalence of age-associated comorbidities and their risk factors between HIV-infected and uninfected individuals: the AGEhIV cohort study. Clin Infect Dis 2014;59:1787-97.

10. Guaraldi G, Orlando G, Zona S, et al. Premature age-related comorbidities among HIV-infected persons compared with the general p. Clin Infect Dis 2011; 53:1120-6.
11. Guaraldi G, Zona S, Brothers TD, et al. Aging with HIV vs. HIV seroconversion at older age: a diverse population with distinct comorbidity profiles. PLoS One 2015;10:e0118531.

12. Pathai S, Bajillan H, Landay AL, et al. Is HIV a model of accelerated or accentuated aging? J Gerontol A Biol Sci Med Sci 2014;69:833-42.

13. Antiretroviral Therapy Cohort Collaboration. Survival of HIV-positive patients starting antiretroviral therapy between 1996 and 2013: a collaborative analysis of cohort studies. Lancet HIV 2017;4:e349-56.

14. Islam FM, Wu J, Jansson J, et al. Relative risk of cardiovascular disease among people living with HIV: a systematic review and meta-analysis. HIV Med 2012; 13:453-68.

15. Silverberg MJ, Leyden WA, Xu L, et al. Immunodeficiency and risk of myocardial infarction among HIV-positive individuals with access to care. J Acquir Immune Defic Syndr 2014;65:160-6.

16. Freiberg MS, Chang $\mathrm{C}-\mathrm{CH}$, Kuller $\mathrm{LH}$, et al. HIV infection and the risk of acute myocardial infarction. JAMA Intern Med 2013;173:614-22.

17. Klein DB, Leyden WA, Xu L, et al. Declining relative risk for myocardial infarction among HIV-positive compared with HIV-negative individuals with access to care. Clin Infect Dis 2015;60:1278-80.

18. Morlat P, Vivot A, Vandenhende MA, et al.; Groupe D'epidémiologie Clinique du Sida en Aquitaine (Gecsa). Role of traditional risk factors and antiretroviral drugs in the incidence of chronic kidney disease, ANRS CO3, Aquitaine Cohort, France, 2004-2012. PLoS One 2013;8:e66223.

19. Medapalli RK, Parikh CR, Gordon K, et al. Comorbid diabetes and the risk of progressive chronic kidney disease in HIV-infected adults: data from the Veterans Aging Cohort Study. J Acquir Immune Defic Syndr 2012;60:393-9.

20. Lucas GM, Lau B, Atta MG, et al. Chronic kidney disease incidence, and progression to end-stage renal disease, in HIV-infected individuals: a tale of two races. J Infect Dis 2008;197:1548-57.

21. Cheung J, Puhr R, Petroumenos K, et al. Chronic kidney disease in Australian HIV-infected patients: analysis of the Australian HIV Observational Database. Nephrology (Carlton) 2017 July 13 [Epub ahead of print]. doi:10.1111/nep.13100.

22. Martin-Iguacel R, Negredo E, Peck R, et al. Hypertension is a key feature of the metabolic syndrome in subjects aging with HIV. Curr Hypertens Rep 2016;18:46.

23. De Wit S, Sabin CA, Weber R, et al.; Data Collection on Adverse Events of AntiHIV Drugs. (D:A:D) study. Incidence and risk factors for new-onset diabetes in HIV-infected patients: the Data Collection on Adverse Events of Anti-HIV Drugs (D:A:D) study. Diabetes Care 2008;31:1224-9.

24. Butt AA, McGinnis K, Rodriguez-Barradas MC, et al.; Veterans Aging Cohort Study. HIV infection and the risk of diabetes mellitus. AIDS 2009;23:1227-34.

25. Brown TT, Cole SR, Li X, et al. Antiretroviral therapy and the prevalence and incidence of diabetes mellitus in the multicenter AIDS cohort study. Arch Intern Med 2005;165:1179-84.

26. Vandenhende MA, Roussillon C, Henard S, et al.; ANRS EN20 Mortalité 2010 study group. Cancer-related causes of death among HIV-infected patients in France in 2010: evolution since 2000. PLoS One 2015;10:e0129550.

27. Shiels MS, Althoff KN, Pfeiffer RM, et al.; North American AIDS Cohort Collaboration on Research and Design (NA-ACCORD) of the International Epidemiologic Databases to Evaluate AIDS (IeDEA). HIV infection, immunosuppression, and age at diagnosis of non-AIDS-defining cancers. Clin Infect Dis 2017;6 4:468-75.

28. Shepherd L, Borges Á, Ledergerber B, et al.; EuroSIDA in EuroCOORD. Infectionrelated and -unrelated malignancies, HIV and the aging population. HIV Med 2016;17:590-600.

29. Cervical screening for dysplasia and cancer in patients with HIV. Baltimore: Clinical Guidelines Program in the JHU School of Medicine, Division of Infectious Diseases; 2018. Available: www.hivguidelines.org/hiv-care/cervical-dysplasia -cancer/ (accessed 2018 June 28).

30. Anal Dysplasia and Cancer Guideline. Baltimore: Clinical Guidelines Program in the JHU School of Medicine, Division of Infectious Diseases; 2007. Available: www.hivguidelines.org/hiv-care/anal-dysplasia-cancer/ (accessed 2018 June 28).

31. Smith CJ, Ryom L, Weber R, et al.; D:A:D Study Group. Trends in underlying causes of death in people with HIV from 1999 to 2011 (D:A:D): a multicohort collaboration. Lancet 2014;384:241-8.

32. Chan AW, Patel YA, Choi S. Aging of the liver: what this means for patients with HIV. Curr HIV/AIDS Rep 2016;13:309-17.

33. Llewllyn A, Simmonds M, Irving WL, et al. Antiretroviral therapy and liver disease progression in HIV and hepatitis $\mathrm{C}$ co-infected patients: a systematic review and meta-analysis. Hepatol Med Policy 2016;1:10.

34. Platt L, Easterbrook P, Gower E, et al. Prevalence and burden of HCV co-infection in people living with HIV: a global systematic review and meta-analysis. Lancet Infect Dis 2016;16:797-808.

35. Rockstroh JK. Non-alcoholic fatty liver disease (NAFLD) and non-alcoholic steatohepatitis (NASH) in HIV. Curr HIV/AIDS Rep 2017;14:47-53. 
36. Morse CG, McLaughlin M, Matthews L, et al. Nonalcoholic steatohepatitis and hepatic fibrosis in HIV-1-monoinfected adults with elevated aminotransferase levels on antiretroviral therapy. Clin Infect Dis 2015;60:1569-78.

37. EACS Guidelines, Version 8.2. Brussels (Belgium): European AIDS Clinical Society; 2017.

38. Antinori A, Arendt G, Becker JT, et al. Updated research nosology for HIVassociated neurocognitive disorders. Neurology 2007;69:1789-99.

39. Heaton RK, Franklin DR, Ellis RJ, et al.; CHARTER Group; HNRC Group. HIVassociated neurocognitive disorders before and during the era of combination antiretroviral therapy: differences in rates, nature, and predictors. J Neurovirol 2011;17:3-16.

40. Sacktor N, Skolasky RL, Seaberg E, et al. Prevalence of HIV-associated neurocognitive disorders in the Multicenter AIDS Cohort Study. Neurology 2016;86:334-40.

41. Jacks A, Wainwright DA, Salazar L, et al. Neurocognitive deficits increase risk of poor retention in care among older adults with newly diagnosed HIV infection. AIDS 2015;29:1711-4.

42. Rockwood K, Howlett SE, MacKnight C, et al. Prevalence, attributes and outcomes of fitness and frailty in community-dwelling older adults: report from the Canadian study of health and aging. J Gerontol A Biol Sci Med Sci 2004;59:1310-7.

43. Rockwood K, Song X, Macknight C, et al. A global clinical measure of fitness and frailty in elderly people. CMAJ 2005;173:489-95.

44. Fried LP, Tangen CM, Walston J, et al.; Cardiovascular Health Study Collaborative Research Group. Frailty in older adults: evidence for a phenotype. J Gerontol A Biol Sci Med Sci 2001;56:M146-56.

45. Gonciulea A, Wang R, Althoff KN, et al. An increased rate of fracture occurs a decade earlier in HIV+ compared with HIV- men. AIDS 2017;31:1435-43.

46. Grund B, Peng G, Gibert CL, et al.; INSIGHT SMART Body Composition Substudy Group. Continuous antiretroviral therapy decreases bone mineral density. AIDS 2009;23:1519-29.

47. Bedimo R, Maalouf NM, Zhang S, et al. Osteoporotic fracture risk associated with cumulative exposure to tenofovir and other antiretroviral agents. AIDS 2012;26:825-31.

48. Bonjoch A, Figueras M, Estany C, et al.; Osteoporosis Study Group. High prevalence of and progression to low bone mineral density in HIV-infected patients: a longitudinal cohort study. AIDS 2010;24:2827-33.

49. McComsey GA, Kendall MA, Tebas P, et al. Alendronate with calcium and vitamin D supplementation is safe and effective for the treatment of decreased bone mineral density in HIV. AIDS 2007;21:2473-82.

50. Aberg JA, Gallant JE, Ghanem KG, et al.; Infectious Diseases Society of America. Primary care guidelines for the management of persons infected with HIV: 2013 update by the HIV Medicine Association of the Infetious Diseases Society of America. Clin Infect Dis 2014;58:1-10.

51. McComsey GA, Tebas P, Shane E, et al. Bone disease in HIV infection: a practical review and recommendations for HIV care providers. Clin Infect Dis 2010;51:937-46.

52. Erlandson KM, Allshouse AA, Jankowski CM, et al. Risk factors for falls in HIVinfected persons. J Acquir Immune Defic Syndr 2012;61:484-9.

53. Talbot LA, Musiol RJ, Witham EK, et al. Falls in young, middle-aged and older community dwelling adults: perceived cause, environmental factors and injury. BMC Public Health 2005;5:86.

54. Geusens $\mathrm{P}$, Autier P, Boonen S, et al. The relationship among history of falls, osteoporosis, and fractures in postmenopausal women. Arch Phys Med Rehabil 2002;83:903-6.

55. Abara WE, Adekeye $\mathrm{OA}, \mathrm{Xu} \mathrm{J}$, et al. Correlates of combination antiretroviral adherence among recently diagnosed older HIV-infected adults between 50 and 64 years. AIDS Behav 2016;20:2674-81.
56. Holtzman C, Armon C, Tedaldi E, et al.; HOPS Investigators. Polypharmacy and risk of antiretroviral drug interactions among the aging HIV-infected population. J Gen Intern Med 2013;28:1302-10.

57. Greene M, Steinman MA, McNicholl IR, et al. Polypharmacy, drug-drug interactions, and potentially inappropriate medications in older adults with human immunodeficiency virus infection. J Am Geriatr Soc 2014;62:447-53.

58. Veilleux O, Lee TC, McDonald E. Rebound adrenal insufficiency after withdrawal of ritonavir in a 65-year-old man using inhaled budesonide. CMAJ 2017;189:E1188-91.

59. Canadian Immunization Guide - Immunization of immunocompromised persons. Ottawa: Public Health Agency of Canada; 2018. Available: www. canada.ca/en/public-health/services/publications/healthy-living/canadian -immunization-guide-part-3-vaccination-specific-populations/page-8-immunization -immunocompromised-persons.html (accessed 2018 Sep. 27).

60. Langebeek N, Kooij KW, Wit FW, et al.; AGEhIV Cohort Study Group. Impact of co-morbidity and aging on health-related quality of life in HIV-positive and HIV-negative individuals. AIDS 2017;31:1471-81.

61. Greysen SR, Horwitz LI, Covinsky KE, et al. Does social isolation predict hospitalization and mortality among HIV+ and uninfected older veterans? J Am Geriatr Soc 2013;61:1456-63.

62. Furlotte C, Schwartz K, Koornstra JJ, et al. 'Got a room for me?' Housing experiences of older adults living with HIV/AIDS in Ottawa. Can J Aging 2012; 31:37-48.

63. Chambers LA, Wilson MG, Rueda S, et al.; Positive Aging Review Team. Evidence informing the intersection of HIV, aging and health: a scoping review. AIDS Behav 2014;18:661-75.

64. Ford CL, Mulatu MS, Godette DC, et al. Trends in HIV testing among U.S. older adults prior to and since release of CDC's routine HIV testing recommendations: national findings from the BRFSS. Public Health Rep 2015;130:514-25.

65. Adekeye OA, Heiman HJ, Onyeabor OS, et al. The new invincibles: HIV screening among older adults in the U.S. PLoS One 2012;7:e43618.

66. Davis T, Teaster PB, Thornton A, et al. Primary care providers' HIV prevention practices among older adults. J Appl Gerontol 2016;35:1325-42.

67. Human immunodeficiency virus - HIV Screening and Testing Guide. Ottawa: Public Health Agency of Canada Government of Canada; (updated 2014 Aug. 05). Available: www.canada.ca/en/public-health/services/hiv-aids/hiv -screening-testing-guide.html (accessed 2018 June 28).

68. Branson BM, Handsfield HH, Lampe MA, et al.; Centers for Disease Control and Prevention (CDC). Revised recommendations for HIV testing of adults, adolescents, and pregnant women in health-care settings. MMWR Recomm Rep 2006; 55:1-17.

69. Abara WE, Adekeye OA, Xu J, et al. Adherence to combination antiretroviral treatment and clinical outcomes in a Medicaid sample of older HIV-infected adults. AIDS Care 2017;29:441-8.

70. Ghidei L, Simone MJ, Salow MJ, et al. Aging, antiretrovirals, and adherence: a meta analysis of adherence among older HIV-infected individuals. Drugs Aging 2013;30:809-19.

71. Ettenhofer ML, Hinkin CH, Castellon SA, et al. Aging, neurocognition, and medication adherence in HIV infection. Am J Geriatr Psychiatry 2009;17:281-90.

72. Bianco JA, Heckman TG, Sutton M, et al. Predicting adherence to antiretroviral therapy in HIV-infected older adults: the moderating role of gender. AIDS Behav 2011;15:1437-46.

73. Conn VS, Ruppar TM, Enriquez M, et al. Medication adherence interventions that target subjects with adherence problems: systematic review and metaanalysis. Res Social Adm Pharm 2016;12:218-46.

74. Katz IT, Maughan-Brown B. Improved life expectance of people living with HIV: who is left behind? Lancet HIV 2017;4:e324-6.
Competing interests: Dr. M. John Gill has served as an ad hoc member on national HIV advisory boards for Viivhealth, Gilead and Merck. No other competing interests were declared.

This article has been peer reviewed.

Affiliations: Department of Medicine (McMillan, Krentz, Gill, Hogan), University of Calgary; Southern Alberta Clinic (Krentz, Gill), Calgary, Alta.
Contributors: All authors contributed to the creation of the research plan and study design. Jacqueline McMillan was responsible for the search strategy, data collection and data extraction. Interpretation of the data was done by all of the authors. The original version of the manuscript was drafted by Jacqueline McMillan with critical revisions and content expertise provided by Hartmut Krentz, M. John Gill and David Hogan. All of the authors read and approved the final version of the manuscript to be published, and agreed to act as guarantors of the results.

Correspondence to: Jacqueline McMillan, jacqueline.mcmillan@ahs.ca 